\title{
The effect of visual isolation on territory size and population density of juvenile rainbow trout (Oncorhynchus mykiss)
}

\author{
I. Imre, J.W.A. Grant, and E.R. Keeley
}

\begin{abstract}
Visibility is thought to affect the territory size of visually oriented animals but there have been few experimental tests of the hypothesis. We re-examined the relationship between visibility and territory size in juvenile salmonids to test the hypothesis that increasing habitat heterogeneity results in a reduction in territory size and consequently in higher population densities. Equal densities of young-of-the-year rainbow trout (Oncorhynchus mykiss) were stocked in two experimental treatments with low visibility and a control treatment with high visibility. Visibility was decreased by placing large stones or plywood dividers onto the substrate of experimental stream channels. As predicted, the size of individual territories decreased with decreasing visibility of the habitat. However, the treatments did not differ significantly in population density or growth rate of the fish. While this study confirms the inverse relationship between habitat visibility and territory size, the decrease in territory size did not produce an increase in population density of juvenile salmonids.
\end{abstract}

Résumé : La visibilité affecte, croit-on, la taille du territoire chez les animaux qui s'orientent par la vue, bien qu'il y ait peu de vérifications expérimentales de cette hypothèse. Nous avons examiné de nouveau la relation qui existe entre la visibilité et la taille du territoire chez des jeunes salmonidés dans le but d'éprouver l'hypothèse selon laquelle une hétérogénéité accrue de l'habitat réduit la taille du territoire et, par conséquent, permet des densités de population plus élevées. Nous avons établi des densités égales de jeunes truites arc-en-ciel (Oncorhynchus mykiss) de l'année dans deux sites expérimentaux à visibilité réduite et un site témoin à visibilité élevée. De grosses pierres ou des panneaux de contre-plaqué placés sur le substrat des ruisseaux artificiels ont servi à diminuer la visibilité. Tel que prédit, la taille des territoires individuels diminue lorsque la visibilité dans l'habitat est réduite. Cependant, il n'en résulte pas de différences dans la densité de population, ni dans le taux de croissance des poissons. Bien que notre étude confirme l'existence d'une relation inverse entre la visibilité dans l'habitat et la taille du territoire, la réduction de la taille du territoire n'entraîne pas d'augmentation de la densité de population chez les jeunes salmonidés.

[Traduit par la Rédaction]

\section{Introduction}

Optimal territory size models (reviewed in Schoener 1983, 1987) have primarily been concerned with predicting how territory size changes in relation to two fundamental factors: food abundance and intruder pressure. Consistent with the predictions of these models, territory size typically increases with decreasing food density (e.g., Stimson 1973; Dill et al. 1981; Hixon 1981) and intruder pressure (e.g., Slaney and Northcote 1974; Myers et al. 1979; Tricas 1989) in a wide variety of taxa.

In addition to food abundance and competitor density, Eason and Stamps (1992) hypothesized that the visibility of the environment will affect the territory size of visually ori-

Received 30 July 2001. Accepted 25 January 2002. Published on the NRC Research Press Web site at http://cjfas.nrc.ca on 5 March 2002.

J16469

I. Imre ${ }^{1}$ and J.W.A. Grant. Department of Biology, Concordia University, 1455 de Maisonneuve Boulevard West, Montreal, QC H3G 1M8, Canada.

E.R. Keeley. Department of Biological Sciences,

Idaho State University, Pocatello, ID 83209, U.S.A.

${ }^{1}$ Corresponding author (e-mail: i_imre@alcor.concordia.ca). ented animals via three mechanisms. First, low visibility may physically constrain an animal to defend a smaller area simply because it cannot see intruders at a distance. Second, the distance at which a central-place forager can detect prey may be reduced so that there is no benefit to defending a large feeding territory in a low-visibility habitat. Third, in a low-visibility environment, territory holders may have to increase their patrol rates to detect and drive out intruders (Eason and Stamps 1992). Any delay in detecting intruders will lead to a greater loss of resources to the intruder and an increase in the cost required to expel the intruder, who quickly begins to feel "at home" on the territory (e.g., Krebs 1982). Such increases in the cost of defense will decrease the optimal territory size (see Schoener 1983, 1987).

Although several previous studies have suggested that habitat visibility affects territory size (reviewed in Eason and Stamps 1992), the experimental evidence to test this hypothesis is scarce. Perhaps the best evidence is that juvenile lizards (Anolis aeneus) defend smaller territories in a low- as compared with a high-visibility environment (Eason and Stamps 1992). In addition, Kalleberg (1958) noted that addition of large stones to a section of a stream aquarium resulted in a decrease in the size of territories and an increase in the density of juvenile Atlantic salmon (Salmo salar). The results of this unreplicated study were interpreted as being 
caused by visual isolation between neighbouring fish. Alternatively, the salmon may have been using the stones as a velocity refuge (Bachman 1984), allowing them to minimize their cost of swimming while having access to a high rate of drifting aquatic invertebrates (e.g., Jenkins 1969; Fausch 1984; Fausch 1993). Kalleberg's (1958) findings are particularly important for salmonid ecologists because, if true, they represent a novel way to increase population density (see Grant et al. 1998).

We examined the relationship between visibility, territory size, and population density using young-of-the-year rainbow trout (Oncorhynchus mykiss) as our test species. Specifically, we tested the prediction that decreasing visibility will result in smaller territories and a higher population density. We attempted to distinguish between the potential effects of visibility and a velocity refuge by adding either large stones, like Kalleberg (1958), or plywood dividers, which provided only visual isolation.

\section{Materials and methods}

\section{Experimental subjects}

On 15 May 2000, 70 pairs of mature rainbow trout were collected from the Blackwater River and stripped of sperm and eggs. The gametes were transported in chilled containers to the Fraser Valley Trout Hatchery $\left(49^{\circ} 0.9^{\prime} \mathrm{N}, 122^{\circ} 16.4^{\prime} \mathrm{W}\right)$ near Abbottsford, B.C., where they were held overnight in a $4^{\circ} \mathrm{C}$ holding room. On 16 May 2000, the eggs from 4-5 females $(10000$ - 15000 eggs $)$ were intermixed with the sperm from 4-5 males. This process was repeated 14 more times, to create a total of 15 groups of embryos. Embryos were held in $7^{\circ} \mathrm{C}$ water until they reached the eyed stage of development. Then they were held at $9.5^{\circ} \mathrm{C}$ until they had absorbed their yolk sac.

On 27 June 2000, approximately 2600 fish were haphazardly sampled from the 15 groups of juvenile rainbow trout at the Fraser Valley Trout Hatchery. The experimental subjects were moved to the Cultus Lake Laboratory $\left(49^{\circ} 3.3^{\prime} \mathrm{N}\right.$, $\left.122^{\circ} 1.4^{\prime} \mathrm{W}\right)$ and held in a fiberglass trough at $13^{\circ} \mathrm{C}$ until they were distributed into the experimental stream channels on 28 June 2000. Fish were fed with dry pelleted fish food (grade 1 Nutra Plus ${ }^{\circledR}$, Moore Clark, Surrey, B.C.) before and during the experiment.

\section{Experimental set-up}

We used 12 experimental stream channels constructed on the outdoor compound of the Cultus Lake Laboratory. Each channel was $5 \mathrm{~m}$ long, $0.92 \mathrm{~m}$ wide, and $0.40 \mathrm{~m}$ deep. Channels were organized into four columns of three in a blocked staircase design (see Keeley 2000). The channels were interconnected with plastic troughs; the outflow of each channel was screened to prevent the escape of fish.

To simulate the shade provided by riparian cover characteristic of headwater streams and to prevent mortality from aerial predators, channels were individually covered with sheets of burlap supported by a wooden frame $1.32 \mathrm{~m}$ above the top edge of each channel. The experimental set-up and water supply are described in more detail by Keeley (2000).

To provide natural water flow conditions for the fish, the bottom of the stream channels was covered with one layer of small $(64-128 \mathrm{~mm})$ and large $(128-256 \mathrm{~mm})$ cobbles (table
5.6 in Gordon et al. 1992). Gaps between cobbles were filled with coarse gravel (32-64 $\mathrm{mm})$ to provide a relatively smooth, natural substrate with minimal visual isolation for fish. The water depth and velocity were measured (at 50\% of the water depth, using a Flo-Mate velocity meter, model 2000, Marsh-McBirney Inc., Frederick, Md.) at three locations along three transects perpendicular to the water flow (Fig. 1). The mean water velocity and mean water depth in each channel was used as a replicate for statistical analyses. Water temperature was measured twice daily (at 07:30 and 16:00) and was maintained at mean \pm standard deviation $12.4 \pm 0.9^{\circ} \mathrm{C}$. End screens were checked and cleaned of debris three times a day. The flow rate in the channels was checked several times daily, and adjusted if necessary.

Each of the 12 channels was subjected to one of three treatments (i.e., 4 replicates per treatment): two treatments with low visibility (cobble and divider, see below) and a control treatment with high visibility. In the cobble treatment, we placed 22 stones (100-165 mm in diameter, 60$100 \mathrm{~mm}$ in height) on top of the substrate, but fully submerged, in a grid arrangement (Fig. 1). This treatment, which was similar to one used by Kalleberg (1958), provided both visual isolation and velocity refuges. In the divider treatment we inserted 22 vertical plywood rectangles (100 mm long, $200 \mathrm{~mm}$ high, and $3 \mathrm{~mm}$ thick) into the substrate parallel to the water flow to provide visual isolation but no velocity refuge (Fig. 1). The control treatment had the basic substrate that provided little or no velocity refuge or visual isolation. The treatments were assigned to the channels to remove any potential effects of the channel position. Each treatment appeared once in the upper, middle, and lower position in the first three columns of channels. The upstream-downstream treatment order in the fourth column was the same as in the first column. After placing the cobbles and the plywood structures into the stream channels, water velocity was measured again across the same transects.

Stream channels were stocked with 213 fish (mean \pm standard deviation fork length $2.59 \pm 0.09 \mathrm{~cm}$ ), corresponding to a percent habitat saturation of $82.4 \%$ (Grant and Kramer 1990). This stocking density (46.3 individuals $\cdot \mathrm{m}^{-2}$ ) approximated the conspecific density that juvenile salmonids would experience shortly after emergence (see review by Grant and Kramer 1990). Fish were assigned randomly to stream channels in groups of 25 individuals.

Since stream-dwelling salmonids feed primarily on drifting aquatic invertebrates (e.g., McNicol et al. 1985; Keeley and Grant 1995), food was presented to fish in a manner similar to stream drift. The daily ration of food was spread evenly on the belt ( $20 \mathrm{~cm}$ wide, $50 \mathrm{~cm}$ long) of an automatic belt feeder (Zeigler Bros. Inc., Gardners, Pa.), that delivered the food $0.5 \mathrm{~m}$ from the upstream end of the stream channel at a constant rate over a period of $12 \mathrm{~h}(07: 00-19: 00)$ to simulate the invertebrate drift during daytime hours. Fish received a daily ration of $1.44 \mathrm{~g}$ of food per stream channel, approximating the maximum abundance of drifting aquatic invertebrates encountered by juvenile salmonids in natural streams (Keeley 2000). Food particles naturally occurring in the lake water were filtered out at the inflow with a $250-\mu \mathrm{m}$ nylon mesh.

At the end of the 10-day experiment (8 July 2000), fish were removed from the stream channels and killed with an 
Fig. 1. General outline of an experimental stream channel. Crosses within circles indicate the position of the cobbles or dividers added to provide velocity refuge and (or) visual isolation in the experimental treatments; solid squares show the location of the water velocity and depth measurements in all treatments. Arrow at top of channel indicates direction of water flow.

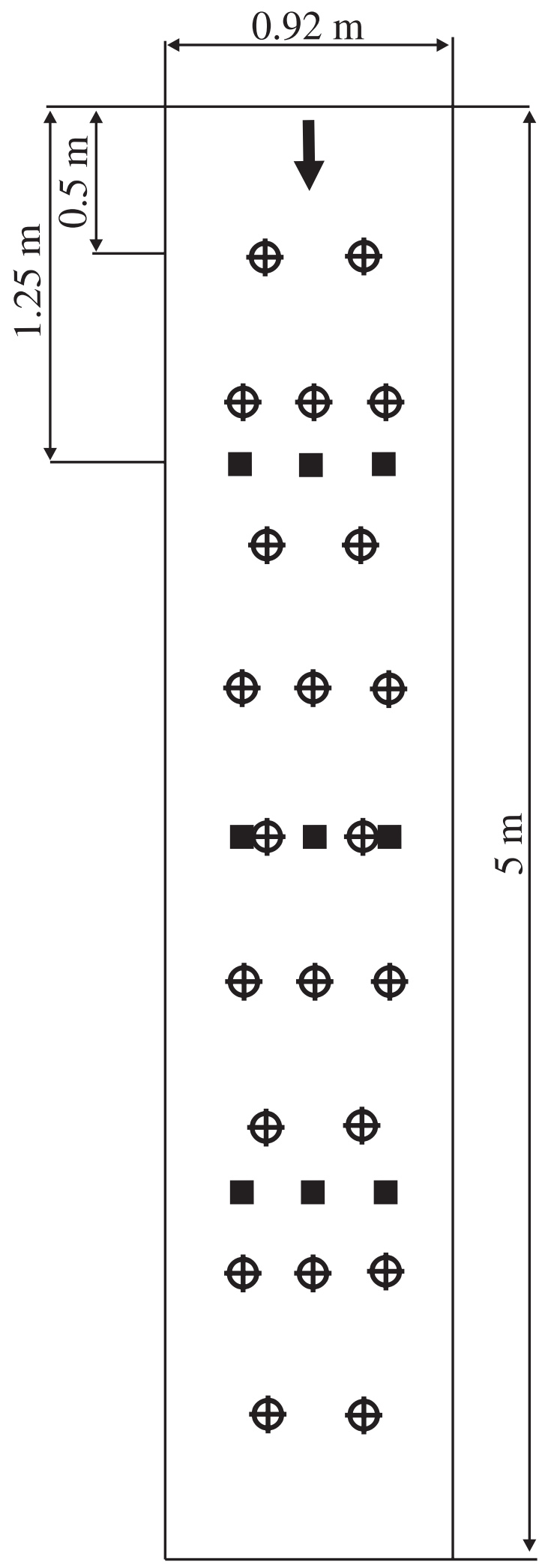

overdose of anaesthetic (Eno, SmithKline Beecham, Oakville, Ont.), as required by the rearing permit issued by the British Columbia Ministry of Fisheries. The final population density in each channel was recorded. To obtain mean fork length and mean weight for each channel, 50 individuals per channel were haphazardly subsampled and measured.

\section{Data collection}

We checked each channel three times daily. Any individuals resting against the downstream end screens were considered to be emigrants and were removed, anesthetized, and their number, fork length (to the nearest $\mathrm{mm}$ ), and weight (to the nearest $0.01 \mathrm{~g}$ ) were recorded. Every second day, 10 fish from each channel were videotaped to compare the body size of residents and emigrants. The actual body length values were extracted from video images as described in Keeley (2000).

To estimate the local population density in the area where the behavioural data were collected, an observer (I. Imre) counted the number of fish in a $1-\mathrm{m}^{2}$ quadrat $(1.09 \times$ $0.92 \mathrm{~m}$ ) positioned $0.8 \mathrm{~m}$ from the upstream end of the channel. Prior to counting, the observer waited for 5 min to allow the fish to return to their initial swimming station and resume their foraging activity (see Grant and Noakes 1987). Fish were counted in each channel on either day 8 or 9 of the experiment.

Behavioural data necessary to calculate territory sizes were collected by videotaping a $0.5 \times 0.5 \mathrm{~m}$ area in the upper half of each stream channel for $30 \mathrm{~min}$ with an S-VHS video camera (on a tripod) inserted through the opening between two consecutive sheets of burlap. The area used for videotaping was within the $1-\mathrm{m}^{2}$ quadrat used for fish counts and was located in the same position in all channels. The first 5 min of each taping session were not used for the reason mentioned above. Only focal individuals (Martin and Bateson 1993) participating in at least five aggressive interactions over the observation period $(25 \mathrm{~min})$ were used for territory size calculations. Territorial fish initiated aggressive interactions and foraging attempts from a single, central, focal point. Aggressive distance was defined as the distance between the focal point of the fish and the position of an intruder when it elicited a chase. Foraging distance was the distance between the focal point of the fish and the position where a food item was captured. We measured 5-10 aggressive distances and 20 foraging distances per focal individual. The actual distances were calculated in relation to grid lines drawn $10 \mathrm{~cm}$ apart on the walls of the channels and a rope (marked at $10-\mathrm{cm}$ intervals) located in the centre of each channel. Territory size based on aggressive data was calculated as the area of a circle, using the mean aggressive distance as the radius (Keeley and Grant 1995; Keeley and McPhail 1998; Keeley 2000). The minimum convex polygon method (Schoener 1981) was used to calculate the size of 95\% foraging areas to confirm the patterns of territory size based on aggressive interactions, as some focal individuals were observed defending their territories only five times. The videotaping sessions were completed during the eighth and ninth day of the experiment.

From the videotapes, we computed the rates of foraging and aggression. To test whether fish with larger territories were able to keep competitors farther away, and hence de- 
fend a larger foraging zone, we measured (to the nearest $\mathrm{mm}$ ) the distance to the nearest neighbour in each of three directions: upstream, left, and right. We did not use data for neighbours downstream of the focal fish, because they rarely chased in that direction (also see Keeley and McPhail 1998; Keeley 2000). From these data the mean distance to the nearest neighbour was calculated for each focal individual.

A mean value for each channel (based on 3-5 focal individuals) was used as a datum when comparing the territory size, aggression rate, foraging rate, and distance to the nearest neighbour among treatments.

\section{Statistical analyses}

One-way analysis of covariance (ANCOVA; with local population density obtained from quadrat counts as a covariate) was used to test for differences in territory size and foraging area among treatments. Foraging and aggression rates, final fork length, final weight, fork length of territorial fish, distance to nearest neighbour, local population density (obtained from quadrat counts) during the experiment, and final population density in the different treatments were compared using a one-way analysis of variance (ANOVA). A paired $t$ test was used to compare the fork length of residents and emigrants (data paired by channel and sampling date), the fork length of territorial fish and other residents in the same channel (data paired by channel), and the length of chases directed towards obstacles vs. open areas (data paired by individual). The assumption of normality was assessed using the Kolmogorov-Smirnov test (with Lilliefors probabilities). Levene's test was used to test the assumption of homogeneity of variances. All statistical tests were performed with Statistica 5.0 (StatSoft Inc. 1995). The critical level of significance was set at 0.05 .

\section{Results}

The average water depth $\left(F_{[2,9]}=0.36, P=0.71\right)$ and current velocity $\left(F_{[2,9]}=2.53, P=0.13\right)$ did not differ significantly among the three treatments (Table 1A). The water velocity was, however, lower immediately downstream of the cobbles, resulting in a tendency for the overall water velocity to be lower in the cobble treatment.

In all three treatments, the fish had a similar distribution pattern. Few fish were within $0.5 \mathrm{~m}$ of the upstream end because of the absence of food and the turbulence of the water. The density of animals was highest just downstream of the food-dispensing location, and then gradually decreased towards the downstream end of each channel.

The number of fish trying to emigrate (Fig. 2) was high during the second and third day of the experiment, but declined thereafter. Floaters, defined as fish that do not feed from a fixed focal point (Puckett and Dill 1985), were present at the beginning of the experiment, but were rarely observed at the end. Most fish had a single, centrally placed focal point from which foraging attempts and aggressive interactions were initiated. However, not all individuals were equally aggressive; the observed frequency of aggression ranged from zero, where individuals held a station but avoided interactions with adjacent fish, to high (maximum aggression rate 2.3 interactions $\cdot \mathrm{min}^{-1}$ ), where focal fish vig- orously excluded all intruders from their territory. In highdensity situations, fish stations were often layered one over another in the water column.

Territory size based on aggressive behaviour decreased with increasing local population density (Fig. 3a, ANCOVA $\left.F_{[1,8]}=13.28, P=0.007\right)$. After statistically controlling for the effect of population density, territory size (Table 1B) differed significantly among treatments (Fig. 3a, ANCOVA $\left.F_{[2,8]}=18.31, P=0.001\right)$. As predicted by the visual isolation hypothesis, territory size was significantly larger in the control treatment than in the low-visibility treatments (contrast analysis between adjusted means $F_{[1,8]}=36.55, P<$ 0.001 ), but territory size did not differ significantly between the divider and cobble treatments (contrast analysis between adjusted means $F_{[1,8]}=0.004, P=0.95$ ). The interaction between territory size and local population density was also not significant (ANCOVA: $F_{[2,6]}=0.49, P=0.63$ ). In total, the ANCOVA model accounted for $85.5 \%$ of the variation in territory size: territory size $\left(\mathrm{m}^{2}\right)=$ intercept $-0.000203 \times$ local density $\left(\mathrm{no} \cdot \mathrm{m}^{-2}\right)$, where the intercept equals 0.0256 , 0.0183 , and 0.0182 for the control, divider, and cobble treatments, respectively.

Foraging area based on a $95 \%$ minimum convex polygon also decreased with increasing local population density (Fig. 3b, ANCOVA $F_{[1,8]}=6.81, P=0.031$ ) and differed among treatments (Fig. $3 b$, ANCOVA $F_{[2,8]}=6.06, P=$ $0.025)$. Foraging area (Table 1B) was larger in the control treatment than in the other two treatments (contrast analysis between adjusted means: $F_{[1,8]}=10.12, P=0.013$ ), and did not differ between the cobble and divider treatments (contrast analysis between adjusted means $F_{[1,8]}=2.50, P=$ $0.15)$, supporting the patterns in territory size. As earlier, the interaction between foraging area and local population density was not significant (ANCOVA $F_{[2,6]}=2.63, P=0.15$ ). The ANCOVA model accounted for $65.7 \%$ of the variation in foraging area: foraging area $\left(\mathrm{m}^{2}\right)=$ intercept $-0.0000554 \times$ local density $\left(\mathrm{no} \cdot \mathrm{m}^{-2}\right)$, where the intercept is 0.00936 , 0.00834 , and 0.00741 for the control, divider, and cobble treatments, respectively. Neither measure of territory size (aggressive data $r=0.04, P=0.81, n=40$; foraging data $r=$ $0.16, P=0.32, n=40$ ) was related to the size of territorial fish, perhaps because of a narrow range in body length (2.4$3.7 \mathrm{~cm}$ ). Rates of aggression (Table $1 \mathrm{~B}, F_{[2,9]}=0.97, P=$ 0.42 ) and foraging (Table $1 \mathrm{~B}, F_{[2,9]}=0.33, P=0.73$ ) did not differ significantly among treatments.

Most focal fish in the low-visibility treatments, and some in the control treatment, had obstructions (i.e., divider, cobble, or side of the channel) in one or two of the three directions (upstream, right, and left), in which aggression occurred frequently. To determine how these obstructions influenced territory size, we compared the chase distances in directions towards obstructions vs. directions with no obstructions. Chases in directions with obstructions (mean \pm standard error $=5.7 \pm 0.51 \mathrm{~cm}$ ) were significantly shorter (paired $t_{14}=3.68, p=0.002, N=15$ ) than chases in directions with no obstructions (mean \pm standard error $6.9 \pm$ $0.56 \mathrm{~cm})$.

The distance to the nearest neighbour did not differ significantly among treatments $\left(F_{[2,9]}=3.40, P=0.08\right)$ but tended to be smaller in the low-visibility treatments (Table 1B). At the level of the individual, however, fish with larger territo- 
Table 1. Descriptive statistics (mean \pm standard error, $n=4$ ) for abiotic and biotic variables in the control, divider, and cobble treatments used to test the effect of visual isolation on territory size and population density in juvenile rainbow trout (Oncorhychus mykiss).

\begin{tabular}{|c|c|c|c|}
\hline (A) Abiotic variables. & Control & Divider & Cobble \\
\hline Water depth $(\mathrm{cm})$ & $11.6 \pm 0.44$ & $11.9 \pm 0.33$ & $11.5 \pm 0.29$ \\
\hline Water velocity $\left(\mathrm{cm} \cdot \mathrm{s}^{-1}\right)$ & $5.3 \pm 0.43$ & $5.1 \pm 0.22$ & $4.4 \pm 0.14$ \\
\hline \multicolumn{4}{|l|}{ (B) Biotic variables. } \\
\hline Territory size (aggressive data) $\left(\mathrm{cm}^{2}\right)$ & $162.0 \pm 16.2$ & $83.2 \pm 11.0$ & $104.9 \pm 17.7$ \\
\hline Territory size (foraging data) $\left(\mathrm{cm}^{2}\right)$ & $67.8 \pm 4.78$ & $56.0 \pm 2.20$ & $53.0 \pm 6.52$ \\
\hline Aggression rate (interactions $\cdot \min ^{-1}$ ) & $0.43 \pm 0.06$ & $0.63 \pm 0.13$ & $0.58 \pm 0.11$ \\
\hline Foraging rate $\left(\right.$ attempts $\left.\cdot \mathrm{min}^{-1}\right)$ & $6.2 \pm 0.46$ & $6.8 \pm 0.57$ & $6.3 \pm 0.46$ \\
\hline Local population density (quadrat counts, no $\cdot \mathrm{m}^{-2}$ ) & $46.6 \pm 5.1$ & $49.3 \pm 6.8$ & $38.1 \pm 5.8$ \\
\hline Final population density $\left(\mathrm{no} \cdot \mathrm{m}^{-2}\right)$ & $25.9 \pm 2.1$ & $27.1 \pm 1.5$ & $23.3 \pm 2.2$ \\
\hline Final fork length $(\mathrm{cm})$ & $3.2 \pm 0.03$ & $3.2 \pm 0.03$ & $3.2 \pm 0.02$ \\
\hline Final body weight $(\mathrm{g})$ & $0.28 \pm 0.004$ & $0.29 \pm 0.013$ & $0.28 \pm 0.007$ \\
\hline Fork length of territorial fish $(\mathrm{cm})$ & $2.9 \pm 0.11$ & $3.0 \pm 0.05$ & $2.9 \pm 0.06$ \\
\hline Distance to nearest neighbour $(\mathrm{cm})$ & $10.8 \pm 1.1$ & $7.9 \pm 0.25$ & $9.8 \pm 0.83$ \\
\hline
\end{tabular}

Fig. 2. Mean number ( \pm standard deviation) of fish caught on end screens over the duration of the experiment in the control $(\bigcirc)$, divider $(\boldsymbol{\square})$, and cobble $(\boldsymbol{\Delta})$ treatments.

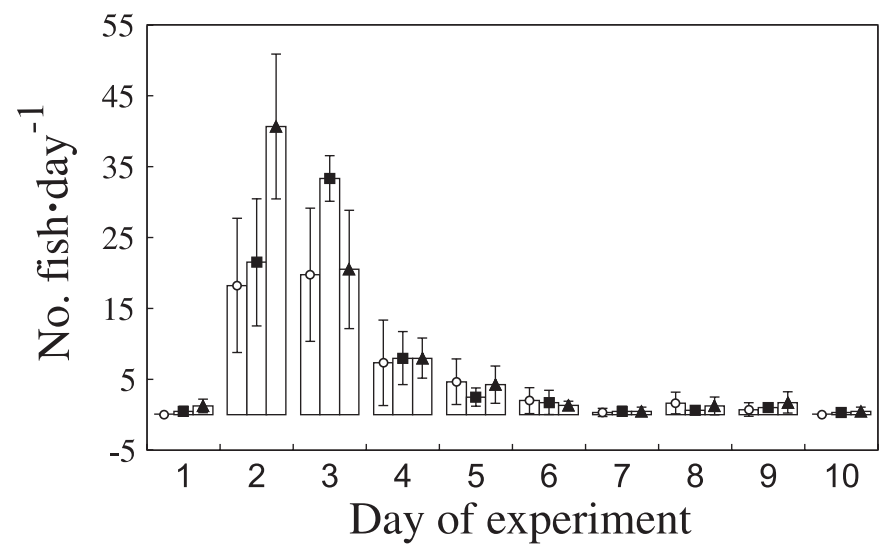

ries were able to keep neighbours farther away ( $r=0.54$, $P=0.0004, n=39)$. Despite differences in territory size, there were no significant differences among treatments in final population density (Table $1 \mathrm{~B}, F_{[2,9]}=1.01, P=0.40$ ) or local fish density obtained from quadrat counts (Table 1B, $\left.F_{[2,9]}=0.98, P=0.41\right)$.

Overall, fish increased in fork length by $\sim 0.6 \mathrm{~cm}(23.2 \%$ of their initial fork length) over the duration of the experiment. Resident fish did not differ significantly in their final fork length (Table $1 \mathrm{~B}, F_{[2,9]}=0.004, P=0.99$ ) or final body weight (Table $1 \mathrm{~B}, F_{[2,9]}=0.21, P=0.82$ ) among treatments. Resident fish were significantly longer than fish collected from end screens (paired $t_{36}=-3.60, P<0.001$ ). Focal fish used for territory size calculations did not differ in fork length among treatments (Table $1 \mathrm{~B}, F_{[2,9]}=0.96, P=0.42$ ), but surprisingly, focal fish were smaller than the average resident in each channel (paired $t_{11}=4.10, P=0.002$ ).

\section{Discussion}

This study contributes to a small but growing body of literature (reviewed by Eason and Stamps 1992) indicating that visibility influences space use. In a seminatural environment
Fig. 3. Relationship between local population density obtained from quadrat counts and territory size based on $(a)$ aggressive data and $(b)$ foraging data for the control $(\bigcirc$, solid line), divider $(\boldsymbol{\square}$, long-dashed line), and cobble $(\diamond$, short-dashed line) treatments. The regression lines are from the analysis of covariance (ANCOVA). The lines for the divider and cobble treatments are virtually identical in $(a)$.

(a)

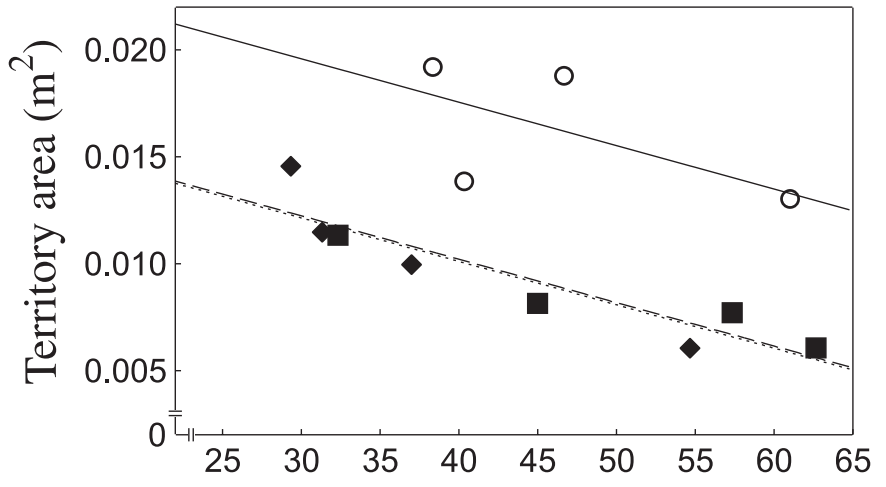

(b)

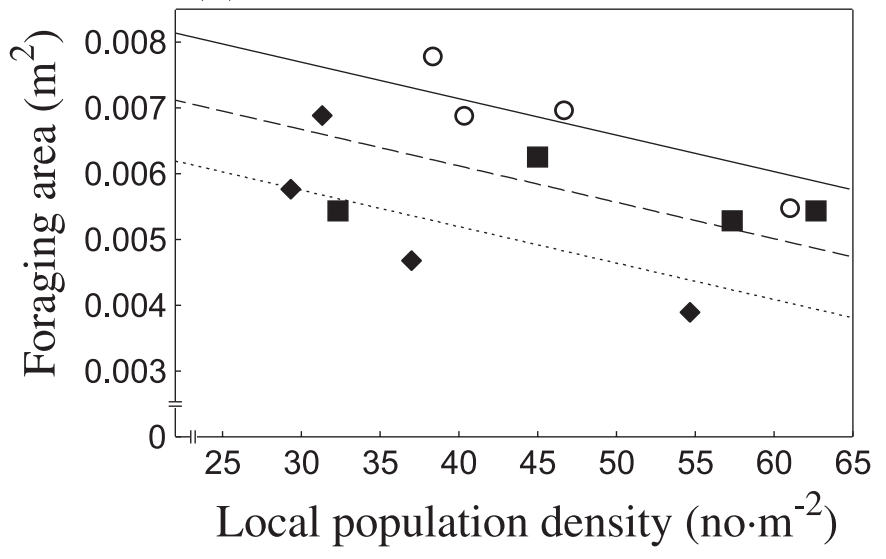

with low visibility, juvenile rainbow trout defended territories that were 0.5 to 0.6 the size of those in the highvisibility control. The similarity in territory size between the 
divider and the cobble treatment suggests that visual isolation rather than a velocity refuge accounts for the reduction in territory size of focal fish. Interestingly, the average territory size of juvenile Atlantic salmon (Salmo salar) (Kalleberg 1958) and Anolis aeneus lizards (Eason and Stamps 1992) in low-visibility environments also decreased to approximately half the size observed in high-visibility environments. To produce an equivalent decrease in territory size as observed in our study (i.e., 37.5-50\% decrease) would require a 3.1- to 5.2-fold increase in food abundance (Grant et al. 1998). Hence, habitat visibility appears to be a powerful way of manipulating territory size.

Rainbow trout in the high-visibility environment defended territories that were on average $67 \%$ of the size predicted by an interspecific relationship for stream-dwelling salmonids (Grant and Kramer 1990) and approximately 20\% of the size defended by wild juvenile steelhead of comparable size (Keeley and McPhail 1998). The relatively small territories observed in our study were likely the result of the high initial stocking density and the high daily food ration (Keeley 2000). As in previous studies (e.g., Slaney and Northcote 1974; Dill et al. 1981; Keeley 2000), territory size decreased with increasing local population density. Surprisingly, we found no relationship between territory size and body size, perhaps because of a narrow range in body size.

Like juvenile lizards (Eason and Stamps 1992), juvenile rainbow trout seemed to avoid visual barriers, so that the barriers were typically near the perimeter of their territories. Nevertheless, these barriers still constrained the size of their territories because their chase distances were shorter in directions toward an obstruction. Similarly, brown trout (Salmo trutta) swimming near or between woody debris had shorter chase distances than conspecifics interacting in a control treatment without woody debris (Sundbaum and Näslund 1998).

In our study, focal fish with larger territories were able to keep neighbours farther away, but this effect did not translate into significant differences in local or final population density. This is in contrast to other studies that have shown a link between territory size and population density of juvenile salmonids (Grant and Kramer 1990; Grant et al. 1998; Keeley 2000). In this study, population density did not differ among treatments, perhaps because fewer than half of the 824 individuals on the videotapes were aggressive at all during the 25-min observation periods and only 3-5 individuals were sufficiently aggressive to warrant the calculation of their territory size. Not all individuals of salmonid populations defend territories (e.g., Puckett and Dill 1985; Grant and Noakes 1988), so the importance of territoriality as a mechanism of population regulation may depend on the proportion of individuals defending territories. Alternatively, it is possible that the proportion of individuals defending territories was sufficient to affect population density, but the experiment was too short to reach the equilibrium density.

The presence of physical structures in the water column often causes local fish abundance to increase (e.g., Saunders and Smith 1962; Fausch and Northcote 1992; Gowan and Fausch 1996), presumably because fish are attracted to the structures for the cover they provide. In contrast, in our study, rainbow trout tended to avoid the cobbles and dividers.
In summary, our study supports the idea that territory size decreases with decreasing visibility. Territorial juvenile rainbow trout in the low-visibility environments held territories that were $\sim 37.5-50 \%$ smaller in size than territories held in the high-visibility control environment, but population density did not differ among treatments.

\section{Acknowledgments}

We are grateful to S.Ó. Steingrímsson, C.A. Johnson, I.L. Girard, L. Weir, and C. Breau for their comments on this study. J.S. Scroggie and M. Phillpotts helped with preparation of the experiment. We thank D. Larson and K. Scheer at the Fraser Valley Trout Hatchery for supplying our experimental subjects and B. Stanton at the Chilliwack River Hatchery for the loan of equipment. Further thanks are due to E. Parkinson (B.C. Ministry of Fisheries) and to Cultus Lake Laboratory (Department of Fisheries and Oceans) for their generous logistical support. The manuscript benefited tremendously from the constructive criticism offered by $\mathrm{C}$. Gowan and an anonymous reviewer. The research was financially supported by an operating grant from the Natural Sciences and Engineering Research Council of Canada (NSERC) to J.W.A. Grant, and a grant from Forest Renewal B.C. to E.R. Keeley. I. Imre was supported by a Natural Sciences and Engineering Research Council postgraduate fellowship and the David J. Azrieli graduate fellowship (from Concordia University) during this study.

\section{References}

Bachman, R.A. 1984. Foraging behaviour of free-ranging wild and hatchery brown trout in a stream. Trans. Am. Fish Soc. 113: 1-32.

Dill, L.M., Ydenberg, R.C., and Fraser, A.H.G. 1981. Food abundance and territory size in juvenile coho salmon (Oncorhynchus kisutch). Can. J. Zool. 59: 1801-1809.

Eason, P.K., and Stamps, J.A. 1992. The effect of visibility on territory size and shape. Behav. Ecol. 3: 166-172.

Fausch, K.D. 1984. Profitable stream positions for salmonids: relating specific growth rate to net energy gain. Can. J. Zool. 62: 441-451.

Fausch, K.D. 1993. Experimental analysis of microhabitat selection by juvenile steelhead (Oncorhynchus mykiss) and coho salmon (O. kisutch) in a British Columbia stream. Can. J. Fish. Aquat. Sci. 50: 1198-1207.

Fausch, K.D., and Northcote, T.G. 1992. Large woody debris and salmonid habitat in a small coastal British Columbia stream. Can. J. Fish. Aquat. Sci. 49: 682-693.

Gordon, N.D., McMahon, T.A., and Finlayson, B.L. 1992. Stream hydrology: an introduction for ecologists. John Wiley \& Sons Ltd., Chichester.

Gowan, C., and Fausch, K.D. 1996. Long-term demographic responses of trout populations to habitat manipulation in six Colorado streams. Ecol. Appl. 6: 931-946.

Grant, J.W.A., and Kramer, D.L. 1990. Territory size as a predictor of the upper limit to population density of juvenile salmonids in streams. Can. J. Fish. Aquat. Sci. 47: 1724-1737.

Grant, J.W.A., and Noakes, D.L.G. 1987. Escape behaviour and use of cover by young-of-the-year brook trout, Salvelinus fontinalis. Can. J. Fish. Aquat. Sci. 44: 1390-1396.

Grant, J.W.A., and Noakes, D.L.G. 1988. Aggressiveness and foraging mode of young-of-the-year brook charr, Salvelinus fontinalis (Pisces, Salmonidae). Behav. Ecol. Sociobiol. 22: 435-445. 
Grant, J.W.A., Steingrímsson, S.Ó., Keeley, E.R., and Cunjak, R.A. 1998. Implications of territory size for the measurement and prediction of salmonid abundance in streams. Can. J. Fish. Aquat. Sci. 55(Suppl. 1): 181-190.

Hixon, M.A. 1981. An experimental analysis of territoriality in the California reef fish Embiotoca jacksoni (Embiotocidae). Copeia, 1981: 653-665.

Jenkins, T.M., Jr. 1969. Social structure, position choice and microdistribution of two trout species (Salmo trutta and Salmo gairdneri) resident in mountain streams. Anim. Behav. Monogr. 2: 56-123.

Kalleberg, H. 1958. Observations in a stream tank of territoriality and competition in juvenile salmon and trout (Salmo salar L., and S. trutta L.). Inst. Freshw. Res. Drottningholm Rep. 39: 55-98.

Keeley, E.R. 2000. An experimental analysis of territory size in juvenile steelhead trout. Anim. Behav. 59: 477-490.

Keeley, E.R., and Grant, J.W.A. 1995. Allometric and environmental correlates of territory size in juvenile Atlantic salmon (Salmo salar). Can. J. Fish. Aquat. Sci. 52: 186-196.

Keeley, E.R., and McPhail, J.D. 1998. Food abundance, intruder pressure, and body size as determinants of territory size in juvenile steelhead trout (Oncorhynchus mykiss). Behaviour, 135: 65-82.

Krebs, J.R. 1982. Territorial defense in the great tit (Parus major): do residents always win? Behav. Ecol. Sociobiol. 11: 185-194.

Martin, P., and Bateson, P. 1993. Measuring behaviour: an introductory guide. 2nd ed. Cambridge University Press, Cambridge.

McNicol, R.E., Scherer, E., and Murkin, E.J. 1985. Quantitative field investigations of feeding and territorial behaviour of young-of-the-year brook charr, Salvelinus fontinalis. Environ. Biol. Fishes, 12: 219-229.

Myers, J.P., Conners, P.G., and Pitelka, F.A. 1979. Territory size in wintering sanderlings: the effects of prey abundance and intruder density. Auk, 96: 551-561.
Puckett, K.J., and Dill, L.M. 1985. The energetics of feeding territoriality in juvenile coho salmon (Oncorhynchus kisutch). Behaviour, 92: 97-111.

Saunders, J.W., and Smith, M.W. 1962. Physical alteration of stream habitat to improve brook trout production. Trans. Am. Fish. Soc. 91: $185-188$.

Schoener, T.W. 1981. An empirically based estimate of home range. Theor. Popul. Biol. 20: 281-325.

Schoener, T.W. 1983. Simple models of optimal-feeding territory size: a reconciliation. Am. Nat. 121: 608-629.

Schoener, T.W. 1987. Time budgets and territory size: some simultaneous optimization models for energy maximizers. Am. Zool. 27: 259-291.

Slaney, P.A., and Northcote, T.G. 1974. Effects of prey abundance on density and territorial behaviour of young rainbow trout (Salmo gairdneri) in laboratory stream channels. J. Fish. Res. Board Can. 31: 1201-1209.

StatSoft Inc. 1995. Statistica for Windows. Vol. 1-5. 2nd ed. StatSoft, Tulsa, Okla.

Stimson, J. 1973. The role of the territory in the ecology of the intertidal limpet Lottia gigantea (Gray). Ecology, 54: 1020-1030.

Sundbaum, K., and Näslund, I. 1998. Effects of woody debris on the growth and behaviour of brown trout in experimental stream channels. Can. J. Zool. 76: 56-61.

Titus, R.G. 1990. Territorial behavior and its role in population regulation of young brown trout (Salmo trutta): new perspectives. Ann. Zool. Fenn. 27: 119-130.

Tricas, T.C. 1989. Determinants of feeding territory size in the corallivorous butterflyfish, Chaetodon multicinctus. Anim. Behav. 37: $830-841$. 